\title{
Vortioxetine Hydrobromide
}

National Cancer Institute

\section{Source}

National Cancer Institute. Vortioxetine Hydrobromide. NCI Thesaurus. Code C125653.

A hydrobromide salt form of vortioxetine, a serotonin (5-HT) modulator and stimulator (SMS), with antidepressant activity. Vortioxetine inhibits the reuptake of serotonin and norepinephrine from the synaptic cleft and acts variably as a serotonin receptor agonist (5-HT1A), partial agonist (5-HT1B) or antagonist (5-HT3, 5-HT1D and 5-HT7). It is not clear how this agent's purported multimodal mechanism of action contributes to its antidepressant effect; however, it is presumed to increase the synaptic availability of serotonin and norepinephrine. 